\title{
Influence of resistance training in quality of life, body composition, and physical performance of community-dwelling elderly women
}

\author{
Iransé Oliveira-Silva', Helton Ramos Gonçalves', Patrícia Espíndola Mota Venâncio', Grassyara Pinho Tolentino', \\ William Alves Lima', Jairo Teixeira Júnior', Rodrigo Franco de Oliveira', Viviane Soares', Matheus Uba Chupel², \\ Deise Aparecida de Almeida Pires-Oliveira
}

\begin{abstract}
Background Aging is an irreversible process by which all living humans will pass, and the percentage of older population growth significantly in the last decades. There are an increasing evidence showing that independently older people, with autonomy and physical capacity, has better quality of life in comparison with others without self-sufficiency. Objective: Verify the changes on Quality-of-Life (QoL), body composition and physical performance (PF) of elderly women submitted to resistance training (RT). Methods: 16 elderly women participated in the study, that consisted in 12 weeks of Resistance training. The QoL with SF-36, the blood pressure (BP), hand-grip strength, anthropometry and physical performance to senior, was measured before and after of resistance training. Results: The main findings of this study were that the RT for 12 weeks are able to changes the self-perception of QoL of elderly women, simultaneously with decrease in percent of fat and increase in strength and PF. In addition, a maintenance of BP levels, flexibility and self-perception of pain and global health (QoL domains), were observed after this period. Conclusion: The study suggest that the 12 weeks of RT, twice a week, is able to ameliorate several physical fitness components and QoL domains, in community-dwelling elderly women.
\end{abstract}

Keywords: Elderly; Quality of Life; Strength; Body Composition; Resistance Trainnning; Physical Performance.

\section{INTRODUCTION}

Aging is an irreversible process by which all living humans will pass, and the percentage of older population growth significantly in the last decades ${ }^{(1)}$. It is estimated that are 600 millions of people with more than 60 years old ${ }^{(2)}$. Together with the increase in aged population comes the incidence of several age-related pathologies, which clearly is a concern for public health. For example, the global costs of Alzheimer Disease increased from 604 billions of dollars in 2010 to 818 billions of dollars in 2015 , growing $35.4 \%{ }^{(3)}$. Attention should be drawn to Brazil, which like the rest of world's-growing economics countries will follow this trend and will have its costs increased significantly ${ }^{(4)}$.

The biological aging (called senescence), implies in several dysfunctions that goes since psychophysiological and sociocultural impairments ${ }^{(5)}$, until loss of functional capacity and independent daily living activities ${ }^{(6)}$. The loss of functional capacity has a direct impact on quality of life $(\mathrm{QoL})^{(6)}$, however, this mechanism may occur by several factors such as impairment in locomotor ${ }^{(7)}$, and psychological domains ${ }^{(8)}$.
There are an increasing evidence showing that independently older people, with autonomy and physical capacity, has better QoL in comparison with others without self-sufficiency ${ }^{(6)}$. The increase in physical activity has been pointed out to be an important tool to improve those conditions cited above in elderly population ${ }^{(10)}$.

Regarding locomotor aspects, it is recognized that the physical inactivity in aged people accelerates the sarcopenia ${ }^{(11)}$, which increase the importance to develop non-pharmacological therapies and practical strategies such as exercise to treat this condition. In this sense, there are a growing body of evidence showing that the resistance training (RT), is a powerful tool to minimize age-related loss of functions, such as functional capacity and muscle performance ${ }^{(12)}$, in immunity ${ }^{(13)}$, and cardiovascular system ${ }^{(14)}$. However, the magnitude of impact of the RT in QoL and their implication in physical fitness (PF) still need to be better understood in an elderly women population. The objective of this study was to verify the changes on QoL, body composition and PF of elderly women submitted to RT. 


\section{METHODS}

\section{Study Design}

This was a prospective, naturalistic study realized in Anápolis (Goiás, Brazil), between March and June of 2017, with previously approval to Ethical Committee of UniEVANGÉLICA (protocol number 1.105.284), where the participants signed consent form to participation in study, and authorized the publication the collective data.

Firstly, a total of 24 participants were recruited. After some of them dropping-out ( 8 participants details are provided below), a sub-total of 16 elderly women (71 \pm 5 years) participated in the study, and were evaluated before (TO) and after (T1) 12 weeks of Resistance training.

\section{Exercise Procedures and Adherence}

The RT sessions were given by a specialist in exercise prescription. The program lasted 12 weeks, and occurred twice a week during this period, totalizing 24 exercise sessions. Sessions took place inside a gymnasium, and consisted in 50 minutes divided in 5 minutes of warm-up, 40 of main part (RT) and 5 minutes of cool-down. All the exercise sessions occurred between 3 p.m. and 5 p.m., according to the participant's availability.

The RT occurred twice-weekly on non-consecutive days, in each session the elderly made a variable sequence of exercise include exercise to trunk, back, upper and lower body. During the first week of the intervention had a familiarization, with a focus on controlled movement and technique. All women made between 11 and 15 maximum repetition in each of the 3 exercise series, and had an individual and progressively increasing load.

\section{Assessments}

All evaluations took place into the laboratory facilities of the University, at baseline and after 12 weeks of RT between $3 \mathrm{pm}$ and $5 \mathrm{pm}$, in the sequence as follows: application of the QoL questionnaire; assessments of blood pressure (BP), anthropometry and body composition; and PF tests.

\section{Quality of Life}

The short version of the SF-36 was used to evaluate the participants' $\mathrm{QoL}^{(15)}$. This tool is composed by 36 items, subdivided into eight dimensions: functional capacity, physical aspects, pain, global health, vitality, social aspects, emotional aspects and mental health. According to the protocol proposed by Ware and Sherbourne ${ }^{(16)}$, for each dimension was obtained a score that ranges from 0 (more disability) to 100 (no disability).

\section{Blood Pressure}

The BP was recorded using a digital sphygmomanometer (MA100, G-Tech, São Paulo, Brazil), following standardization procedures $^{(17)}$. The systolic blood pressure (SBP) and diastolic blood pressure (DBP) were verified after five minutes of rest in sit position.

\section{Hand-Grip Strength}

The hand-grip strength (HGT) was measured using a dynamometer (Jackson, Jamar ${ }^{\circledR}$, USA), in both hands. The test was applied twice, with 30 seconds of rest, and the average value of the two measurements were recorded by each hand. The procedures for HGT assessment followed the guidelines described by the American Society of Hand Therapist's ${ }^{(18)}$.

\section{Anthropometry}

A scale (PL 200, Filizola, Recife, Brazil), and a stadiometer (Seca, Sanny, São Paulo, Brazil), were used to determine the participants' body mass and height, respectively. These variables were used to calculate the body mass index (BMI) by the equation [(BMl=body mass $\mathrm{Kg} /$ height $\left.\left.\mathrm{m}^{2}\right)\right]$. Once the skinfold measurements were done using an adipometer caliper (Langue, Cambridge Scientific Industries, USA), the body density was determined by the equation of Jackson and Pollock ${ }^{(19)}$.

\section{Physical Fitness}

The Senior Fitness Test was used to evaluate the PF of the participants ${ }^{(20)}$, using a set stations in a circuit style. Firstly, was explained to the participant all the procedures. Secondly, ten minutes of warm-up was made to prepare the subject. Briefly, the sequence of tests occurred as follows and consisted on:

8-foot up and Go Test (8-FGT): that evaluates the agility and dynamic balance and consists in the time of participants' need to get-up the chair, walk around either side of a marker placed 244 centimeters away, and sit back; 30's chair-and stand test (30s-CS): that measures the lower body strength through the number of stands completed in 30 seconds;

30 's arm-curl test (30s-AC): the upper body strength is measured by this test, which consist in the number of arm curls executed in 30 seconds in seated position. The participants' perform this test by both (left and right) arms; 6 minutes walking test (6WT): the aim of this test was to evaluate the distance walked during 6 minutes. The participants' set their own pace and were able to stop for rest if they desire. Chair sit-and-reach test (CSR): the lower body flexibility of both legs was evaluated by CSR, that measure the distance in centimeters between the tip of the fingertips and the toes. When the fingertips touch toes were attributed the score zero, and if do not touch, a negative score was attributed by measuring the centimeters far from each other. If the fingertips overlap the toes, the score is positive; Back Scratch Test (BST): the BST was applied to evaluate the upper body flexibility, and measures how close the hands can be brought together behind the back. The score was record in centimeters, for both hands, in the same principles of the CSR. 


\section{Statistical Analysis}

Descriptive statistics are presented in means \pm standard deviation. Normality was check through Kolmogorov Smirnov test with Liliefors correction. A paired t-test was done to verify differences in means between moments. The percentage of change was calculated [(Post-value/Pre-value)-1], and presented for each parameter. In addition, the magnitude of changes was verified thought Cohen's $d$ effect size (ES), and categorized as trivial ( $d 0.2)$, small ( $d 0.2$ to 0.6 ), moderate ( $d 0.6$ to 1.2 ), large ( $d 1.2$ to 2.0 ), very large ( $d 2.0$ to 4.0 ) and nearly perfect $(d>4.0)^{(21)}$. The statistical analysis was performed using the Statistical Package for Social Sciences (IBM, SPSS, version 22, USA), and level of significance was set at $p<0.05$.

\section{RESULTS}

Participants characteristics are presented in Table 1. Table 2 presents the results for QoL domains evaluated through SF-36 questionnaire.

Table 1. Characteristics of participants

\begin{tabular}{ccc} 
& Mean \pm sd & Min-Max \\
\hline Age (year) & $71 \pm 5$ & $63-78$ \\
Body mass (kg) & $60.2 \pm 9.8$ & $47-70$ \\
Height $(\mathrm{m})$ & $1.52 \pm 0.05$ & $1.46-1.60$ \\
BMI (kg/m $\left.{ }^{2}\right)$ & $25 \pm 2$ & $21-29$ \\
Marital Status & Single: $1(6 \%) ;$ Married: $10(62 \%) ;$ Divorced: $5(32 \%)$ \\
Educational & Primary: $10(62 \%) ;$ Secondary: 4(25\%); College: $2(13 \%)$ \\
\hline School &
\end{tabular}

Note: Body mass index-BMI;
No adverse effects were experienced for the participants during the exercise program; however, as previously expected for exercise interventions with elderly people some drop-out occurred during the 12 weeks. From the 24 who started the exercise program, 8 dropped-out the intervention due health problems, infrequence to training and change of home.

Significant differences with moderate effects sizes ( $d 0.6$ to 1.2 ), were observed after intervention for several domains of SF-36, such as functional capacity, physical, social and emotional aspects, and mental health $(p<0.05)$. Means for vitality also increase significantly with large magnitude of effect ( $p<0.01, d=1.48$ ). No differences were observed for pain and global health ( $p>0.05)$. Results for cardiometabolic parameters and body composition are presented in Table 3.

No differences were found after 12 weeks of intervention for BP parameters ( $p>0.05$ ). However, BMI and \%Fat decrease significantly after the exercise program $(p<0.05)$. In fact, a moderate effect size was observed for \%fat changes in mean after intervention $(d=0.68)$. Changes for PF parameters are presented in Table 4.

After intervention, significant increase with large magnitude of effect ( $d 1.2$ to 2.0), were observed for 30s- Chair Stand Test, 30s- Biceps Curl Test and Hand Grip Test - with non-dominant hand $(p<0.05)$. The time for Time Up-and-Go test decrease moderately after intervention $(p<0.05, d=1.20)$, simultaneously with a significant increase in walking distance on 6 -mWALK test $(p<0.05, d=0.69)$. No significant changes were observed after intervention for CSR and BST ( $p=0.97$ and $p=0.15$, respectively).

Table 2. Changes in Quality of Life domains after 12 weeks of Exercise

\begin{tabular}{|c|c|c|c|c|c|}
\hline & Baseline & After 12 weeks & $\Delta \%$ & $P$ & ES \\
\hline Functional capacity & $86 \pm 13(60-100)$ & $95 \pm 9(75-100)$ & 6.8 & .00 & 0.84 \\
\hline Physical aspects & $64 \pm 30(25-100)$ & $89 \pm 27(25-100)$ & 21.8 & .02 & 0.87 \\
\hline Pain & $70 \pm 26(20-100)$ & $72 \pm 31(11-100)$ & 3.8 & .79 & 0.07 \\
\hline General health & $72 \pm 26(62-77)$ & $73 \pm 14(40-80)$ & 1.6 & .81 & 0.05 \\
\hline Vitality & $65 \pm 26(20-95)$ & $93 \pm 6(80-100)$ & 25.1 & .00 & 1.48 \\
\hline Social aspects & $77 \pm 30(13-100)$ & $98 \pm 4(88-100)$ & 18.6 & .01 & 0.98 \\
\hline Emotional aspects & $62 \pm 43(0-100)$ & $90 \pm 24(34-100)$ & 25.2 & .05 & 0.81 \\
\hline Mental health & $78 \pm 19(40-100)$ & $94 \pm 7(80-100)$ & 13.5 & .00 & 1.13 \\
\hline
\end{tabular}

Table 3. Blood pressure and Body Composition

\begin{tabular}{|c|c|c|c|c|c|}
\hline & Baseline & After 12 weeks & $\Delta$ & $P$ & ES \\
\hline SBP & $117 \pm 7(110-130)$ & $115 \pm 5(110-120)$ & -1.25 & .43 & 0.14 \\
\hline DBP & $68 \pm 8(60-80)$ & $72 \pm 7(60-80)$ & 2.50 & .54 & 0.25 \\
\hline BMI & $25 \pm 2(21-29)$ & $24 \pm 3(19-28)$ & -1.24 & .03 & 0.19 \\
\hline$\%$ fat & $27.1 \pm 1.8(25-30)$ & $23.8 \pm 1.6(22-26)$ & -2.88 & .00 & 0.68 \\
\hline
\end{tabular}

Note: Systolic Blood Pressure; DBP: Diastolic Blood Pressure; BMI: Body mass index; \%fat: fat percentual. 
Table 4. Physical Fitness battery tests and Hand-Grip test, before and after intervention.

\begin{tabular}{|c|c|c|c|c|c|}
\hline & Baseline & After 12 weeks & $\Delta$ & $P$ & ES \\
\hline Chair Stand Test (n) & $14 \pm 2(11-17)$ & $17 \pm 1(15-20)$ & 3.63 & .00 & 1.89 \\
\hline Biceps Curl Test (n) & $18 \pm 1(16-20)$ & $20 \pm 1(19-23)$ & 2.88 & .00 & 2.00 \\
\hline Chair Sit Reach Test (cm) & $-6 \pm 6(-18-0)$ & $-5 \pm 6(-18-0)$ & 1.63 & .97 & 0.16 \\
\hline Back Scratch Test $(\mathrm{cm})$ & $-6 \pm 6(-18-0)$ & $-4 \pm 3(-9-0)$ & 2.38 & .15 & .42 \\
\hline Time up and Go Test (sec) & $5.7 \pm 0.5(5-6.5)$ & $5.1 \pm 0.5(4.2-5.7)$ & -0.55 & .00 & 1.20 \\
\hline 6-minute Walk Test $(\mathrm{m})$ & $506 \pm 72(345-563)$ & $562 \pm 89(355-625)$ & 52.8 & .00 & 0.69 \\
\hline \multicolumn{6}{|l|}{ Hand Grip Test } \\
\hline Power dominant hand & $22 \pm 2(19-26)$ & $23 \pm 2(20-27)$ & 1.63 & .00 & 0.50 \\
\hline Power non dominant hand & $24 \pm 2(20-27)$ & $27 \pm 2(24-30)$ & 2.13 & .00 & 1.50 \\
\hline
\end{tabular}

\section{DISCUSSION}

The main findings of this study were that the RT for 12 weeks are able to changes the self-perception of QoL of elderly women, simultaneously with decrease in percent of fat and increase in strength and PF. In addition, a maintenance of BP levels, flexibility and self-perception of pain and global health QoL, were observed after this period.

Our results highlights the well-established knowledge regarding the benefits of regular exercise practice for elderly population ${ }^{(10,12,22)}$, but add new information concerning RT during 12 weeks for promote changes in QoL and PF, which are different from other studies with this population ${ }^{(23)}$. Some authors point that long periods of training (more than twelve-weeks) are needed to provide enough information or changes in those parameters evaluated ${ }^{(24)}$. RT has several benefits for elderly population, that ranges from attenuation of loss in muscle mass occurred during aging ${ }^{(25)}$, until increase in muscle strength ${ }^{(26)}$. Scientific evidence with this type of training shows that even in old adults with frailty condition, there is possible to increase the functional mobility and muscle size ${ }^{(27)}$.

Our results suggest that there are some influence of the RT in modulate changes in self-perception of QoL of elderly. However, due the study design adopted for this intervention, it is impossible to conclude if the physical training (alone) was the only mechanism proposed to cause this changes, since the social relationship of the participants could contribute significantly to increase QoL $^{(6)}$. We can have hypothesized also that could be an additional factor the extrinsic motivation given by the research team who interact with the subjects to increase QoL parameters. In this case, we recommend further studies to investigate these possibilities.

Regarding BP, no significant changes were observed, which was expected according to the literature available for this population ${ }^{(28)}$. However, it is necessary to highlight the role that the regular physical exercise exert on $\mathrm{BP}$, because aging causes several biological changes who impair the cardiovascular system, but it is well established that regular exercise practice can attenuate this changes ${ }^{(21)}$.
Other important results in this study were the changes modulated by RT intervention on PF parameters. The baseline levels of PF in the participants of this study are better than other investigations in elderly population ${ }^{(6,13)}$. There was a substantial influence of this type of exercise on strength, aerobic resistance, dynamic balance, and other parameters who contribute significantly to increase the physical autonomy of elderly population ${ }^{(29)}$. Other studies involving institutionalized elderly population showed that even exercise using elastic bands can increase PF significantly ${ }^{(13)}$. The same authors showed that even the maintenance of some PF parameters in elderly is a solid benefit in comparison who those that are sedentary and impair their physical condition over time. Regarding flexibility tests, however, our data showed that there were not influenced by the intervention, which suggest the importance to include the stretching exercises on exercise programs to act directly on this bodily function of elderly population.

Despite the strength of this study's conclusion, there were some limitations. Firstly, the absence of a control group limits the comparison over time of people who does physical training that those who does not. Secondly, the small sample size restricts the magnitude of effect in some parameters evaluated.

\section{CONCLUSION}

In conclusion, this study suggest that the 12 weeks of RT, twice a week, is able to ameliorate several PF components and QoL domains, in community-dwelling elderly women.

\section{AUTHOR CONTRIBUTIONS}

IOS, study design, data collection, data analysis and interpretation of the results, writing of the manuscript. HRG, study design, data analysis and interpretation of the results, writing of the manuscript. PEMV, data analysis and interpretation of the results, writing of the manuscript. PEMV, GPT, WAL, JTJ, RFO, VS, data analysis and interpretation of the results, writing of the manuscript. MUC, data analysis and interpretation of the results, review all manuscript. DAAPO, study design, data analysis and interpretation of the results, writing of the manuscript. 


\section{CONFLICTS OF INTEREST}

Nothing to declare.

\section{AUTHOR DETAILS}

${ }^{2}$ Faculty of Sport Science and Physical Education, Universidade de Coimbra, Coimbra, Portugal

\section{REFERENCE}

1. Ilmarinen J. The ageing Workforce challenges for occupational health. Occupational Medicine. 8:362-364. 2016.

2. Ghasemi M, Dehaghani RA. Mehrabi T. Investigating the effect of education based on need to prevent falling during activities of daily living among the elderlies referring to health centers of Isfahan. Iran J Nurs Midwifery Res. 21(4):430-435. 2016.

3. Wimo A, Guerchet M, Ali GC, Wu YT, Prina AM, Winblad B et al. The worldwide costs of dementia 2015 and comparisons with 2010. Alzheimer's and Dementia. 13(1):1-7. 2017.

4. Miranda GMD, Mendes ACG, Silva ALA, Miranda GMD, Mendes ACG, Silva ALA. Population aging in Brazil: current and future social challenges and consequences. Revista Brasileira de Geriatria e Gerontologia. 19(3):507519. 2016

5. Ciosak SI, Braz E, Costa MFBNA, Nakano NGR, Rodrigues J, Alencar RA et al. Senescência e senilidade: novo paradigma na atenção básica de saúde. Rev. Esc. Enferm. USP. 45(2):1763-8. 2011.

6. Furtado GE, Uba-Chupel M, Carvalho HM, Souza NR, Ferreira JP, Teixeira AM. Effects of a chair-yoga exercises on stress hormone levels, daily life activities, falls and physical fitness in institutionalized older adults. Complementary Therapies in Clinical Practice. 24:123-129. 2016.

7. Gouveia OMR, Matos AD, Schouten MJ. Redes sociais e qualidade de vida dos idosos: uma revisão e análise crítica da literatura social. Rev. Bras. Geriatr. Gerontol. 19(6):1030-40. 2016

8. Ribeiro F, Gomes S, Teixeira F, Brochado G, Oliveira J. Impacto da prática regular de exercício físico no equilíbrio, mobilidade funcional e risco de queda em idosos institucionalizados. Rev. Port. Cien. Desp. 9(1):36-42. 2009.

9. Gonçalves LHT, Nassar SM, Daussy MFS, Santos SMA, Alvarez AM. O convívio familiar do idoso na quarta idade e seu cuidador. Cienc. Cuid. Saúde. 10(4):746-54. 2011.

10. Oliveira-Silva I, Arcanjo, LRB. Papel da hidroginástica na capacidade funcional de idosos - Role of hydrogymnastic in the functional capacity of elderly. Rev. Educ. Saúde 5(1): 15-20. 2017

11. Mastaglia S. Osteosarcopenia: unfactor de riesgo para fracturas osteoporóticas. Acta bioquím. clín. latinoam. 50(3). 2016.

12. Antoniak $A E$, Greig $C A$. The effect of combined resistance exercise training and vitamin $D_{3}$ supplementation on musculoskeletal health and function in older adults: a systematic review and meta-analysis. BMJ Open. 7(7):e014619. 2017.

13. Chupel MU, Direito F, Furtado GE, Minuzzi LG, Filipa M, Colado J. Et al. Strength Training Decreases Inflammation and Increases Cognition and Physical Fitness in Older Women with Cognitive Impairment. Frontiers in Physiology. 8(6):1-13. 2017.
14. Dantas FFO, Brasileiro-Santos Mdo S, Batista RMF, Do Nascimento LS, Castellano LRC, Ritti-Dias RM. Et al. Effect of strength training on oxidative stress and the correlation of the same with forearm vasodilatation and blood pressure of hypertensive elderly women: A randomized clinical trial. PLoS ONE. 11(8):1-19. 2016.

15. Ciconelli RM. Tradução para o português e validação do questionário genérico de avaliação de qualidade de vida "Medical Outcomes Study 36-Item Short-Form Health Survey (SF-36)". São Paulo, 1997. 148 p. Tese (Doutorado em Medicina) - Escola Paulista de Medicina, Universidade Federal de São Paulo. São Paulo, 1997.

16. Ware JE Jr, Sherbourne D. The MOS 36-item short-form health survey (SF36). I. Conceptual framework and item selection. Med Care. 30:473-481. 1992.

17. Sociedade Brasileira de Cardiologia (SBC). V diretrizes de monitorização ambulatorial da pressão arterial (MAPA) e III diretrizes de monitorização residencial da pressão arterial (MRPA). 97(3):Supl.3. 2011.

18. Fees E, Moran C. Clinical assessment recommendations. American society of hand therapists. 1981.

19. Jackson AS, Pollock ML. Generalized equations for predicting body density of men. British Journal of Nutrition. 40: 497-504. 1978.

20. Rikli RE, Jones JC. Teste de Aptidão Física para Idosos. Human Kinetics. (Tradução de Sonia Regina de Castro Bidutte), Manole. São Paulo. 2008.

21. Hopkins WG, Marshall SW, Batterham AM, Hanin J. Progressive statistics for studies in sports medicine and exercise science. Medicine and Science in Sports and Exercise. 41(1):3-12. 2009.

22. Garatachea N, Pareja-Galeano H, Sanchis-Gomar F, Santos-Lozano A, Fiuza-Luces C, Morán M et al. Exercise Attenuates the Major Hallmarks of Aging. Rejuvenation Research. 18(1):57-89. 2015.

23. Latorre PA, Santos MA, Heredia Jimenez JM, Delgado Fernandez M, Soto VM et al. Effect of a 24-week physical training programme (in water and on land) on pain, functional capacity, body composition and quality of life in women with fibromyalgia. Clin Exp Rheumatol. 31(6 Suppl 79):S72-80. 2013.

24. Carbonell-Baeza A, Aparicio VA, Chillón P, Femia P, Delgado-Fernandez M, Ruiz Júnior. Effectiveness of multidisciplinary therapy on symptomatology and quality of life in women with fibromyalgia. Clin Exp Rheumatol. 29 (Suppl. 69): S97-103. 2011.

25. Tseng BS, Marsh DR, Hamilton MT, Booth FW. Strength and aerobic training attenuate muscle wasting and improve resistance to the development of disability with aging. The journals of gerontology. Series A, Biological sciences and medical sciences. 50(1993):113-119. 1995.

26. Morganti CM, Nelson ME, Fiatarone MA, Dallal GE, Economos CD, Crawford BM et al. Strength improvements with 1 year of progressive resistance training in older women. Medicine \& Science in Sports \& Exercise. 27(6):906-912. 1995.

27. Fiatarone MA. High-Intensity Strength Training in Nonagenarians. JAMA. 263(22):3029-34. 1990

28. De Souza CA, Shapiro LF, Clevenger CM, Dinenno FA, Monahan KD, Tanaka $\mathrm{H}$ et al. Regular aerobic exercise prevents and restores age-related declines in endothelium-dependent vasodilation in healthy men. Circulation. 102:1351-1357. 2000

29. Manini TM, Pahor M. Physical activity and maintaining physical function in older adults. British journal of sports medicine. 43(1):28-31. 2009 